\title{
Patient attitudes regarding pca and associated costs
}

Neal H Badner MD FRCPC,

\begin{abstract}
Purpose: To determine patients' knowledge and attitudes towards patient-controlled analgesia (PCA) costs through the use of our acute pain service quality assurance (QA) programme.

Methods: Quality Assurance questionnaires were distributed to all patients receiving PCA opionds for $>12 \mathrm{hr}$. Patients were asked to note the presence of side effects (nausea/Nomiting, pruritus, urinary retention), to indicate their satisfaction with regard to their pain relief, follow-up assessments, treatment of side effects, and to recall the previous method of pain relief and their satisfaction with it. Patients were also asked to estimate the total cost of PCA $(0-\$ 50, \$ 50-100, \$ 100-200,>\$ 200)$, and what amount if any they would be willing to pay $(0-\$ 50$. $\$ 50-100, \$ 100-200,>\$ 200)$. Results obtained over a recent four month period were reviewed.

Results: One hundred and thirty-three questionnaires were distributed and $103(77 \%)$ were returned. The percentage of patients rating their satisfaction as very good or excellent was $86 \%$ for pain relief. $96 \%$ for followup, $71 \%$ for side effect treatment, but only $43 \%$ for their previous surgical pain relief $(P<0.001)$. The distribution of cost estimates was $10 \% \$ 50-100,37 \% \$ 100-200$ and $53 \%>\$ 200$ with $60 \%$ willing to pay a portion of this cost. Those willing to pay were more likely to have had very good or excellent pain relief $(94 \%$ vs $71 \%$. $P<0.05)$ and treatment of side effects $(71 \%$ vs $48 \%, P<0.05$ ) than those not willing to pay.

Conclusions: Patients continue to be highly satisfied with PCA therapy and are aware of the costs involved. A majority of patients were willing to pay to obtain this service if necessary. Patients who had poorer pain relief and less efficacious treatment of their side effects were less willing to pay.
\end{abstract}

Objectif : Préciser les connaissances et les attitudes du patient à l'égard des coûts de l'auto-analgésie (PCA) procurée par un service de gestion de la douleur aiguë en fonction du programme d'assurance-qualité.

Méthodes : Des questionnaires pertinents à l'assurance-qualité ont été distribués à tous les patients recevant un morphinique en PCA pour plus de $12 \mathrm{~h}$. Les patients devaient y noter l'existence d'effets secondaires (nausées, vomissements, prurit, rétention urinaire), le degré de satisfaction quant au soulagement, au suivi, au traitement des effets secondaires et comparer la méthode antérieure de traitement de la douleur et le degré de satisfaction obtenu avec celle-ci. On leur demandait aussi d'évaluer le coût total de la PCA (0-50\$. 50-100\$, 100-200\$. $>200 \$)$ et le montant qu'ils seraient prêts à payer (0-50\$,50-100\$, 100-200\$, >200\$) éventuellement pour ce service. Cette étude visait une période récente de quatre mois.

Résultats : Cent trente-trois questionnaires ont été distribués dont 103 (77\%) sont revenus complétés. Le pourcentage de patients dont le degré de satisfaction était jugé de très grand à excellent était de $86 \%$ pour le soulagement de la douleur, $96 \%$ pour le suivi, $71 \%$ pour le traitement des effets secondaires, mais seulement $43 \%$ pour la méthode utilisée pour soulager la douleur dans le passé $(P<0.001)$. La distribution de l'appréciation du coût était de 10\%,50-100\$. 37\%,100-200 et 53\%, 200\$ et plus. Le degré de soulagement de la douleur de très bon à excellent ( $94 \%$ vs $71 \%, P<0,05)$ et le traitement des effets secondaires $(71 \%$ vs $48 \%$. $P<0,05$ ) déterminaient ceux qui étaient les plus susceptibles d'accepter de payer.

Conclusions : Les patients continuent d'être très satisfaits de la PCA et en connaissent le prix. Si nécessaire, la majorité d'entre sont prêts à en défrayer les coûts. Les patients dont le soulagement de la douleur et le traitement des effets secondaires avaient été jugés moins efficaces étaient les moins disposés à payer.

From the Department of Anacsthesia, London Health Sciences Centre, Universiry Campus, University of Western Ontario, London, Ontario.

Address correspondence to: Dr. N.H. Badncr, Department of Anaesthesia, University Campus, London Health Sciences Centre, 339 Windermere Road, London, Ontario, Canada N6A 5 A5.

Phone: 519-663-3022; Fax: 519-663-3079; E-mail: nbadner@julian.uwo.ca

Accepted for publication on November 30, 1996. 
$\mathrm{T}$

HE last decade has seen the widespread development of acute pain services in Canada, ${ }^{1}$ United States, ${ }^{2}$ and Europe ${ }^{3}$ which use patient-controlled analgesia (PCA) as their primary modality. This has occurred because of the continued deficiency of the pro re nato (prn) method of prescribing, ${ }^{4}$ and lack of nursing knowledge of pain management principles, ${ }^{5}$ combined with the fact that a majority of hospital patients still cite pain after surgery as their primary fear. ${ }^{2}$ Initially touted as being able to decrease opioid usage and decrease hospital stay, further studies have shown that PCA leads to increased patient satisfaction and greater analgesic efficacy when compared with im injections. ${ }^{6}$

More recently, many treatment modalities are either currently undergoing cost-effectiveness analyses or being suggested to do so. ${ }^{7}$ Early studies have suggested that PCA is more cost-effective than either im or epidural analgesia. ${ }^{8-10}$ Patients, however, are not involved with this process. Our acute pain service maintains a quality assurance (QA) programme to evaluate care by the use of questionnaires. We recently modified our questionnaire to determine our patients' knowledge and attitudes towards PCA costs and report our findings here.

\section{Methods}

Patients receiving PCA therapy at our institution have the process initiated by the attending anaesthetist and treatment is started in the post-anaesthesia care unit (PACU). Our PCA therapy usually consists of $1-2 \mathrm{mg}$ morphine, though occasionally $10-20 \mu \mathrm{g}$ fentanyl or $10-20 \mathrm{mg}$ demerol is used when side effects to morphine are known or encountered. All the above are used with lockout intervals of 5-10 min. Basal infusions are not routinely utilized. The cost of this service has been estimated at approximately $\$ 150 /$ patient (see Appendix).

Quality assurance questionnaires were distributed to all patients receiving PCA opioids for $>12 \mathrm{hr}$. Patients were asked to note the presence (yes/no) of side effects (nausea/vomiting, pruritus, urinary retention), to indicate their satisfaction (excellent, very good, good, fair, poor, don't know) with regards to their PCA pain relief, its convenience and applicability, follow-up care received, treatment of side effects, and satisfaction with any previous surgical pain relief they had received. They were also asked to comment (strongly agree, somewhat agree, somewhat disagree, strongly disagree) on whether they would request this therapy in the future, whether they were satisfied overall, and whether they would recommend PCA use to others. Patients were also asked to estimate the total cost of PCA $(0-\$ 50, \$ 50-100, \$ 100-200,>\$ 200)$, whether, if necessary, they would pay for this service, and if so, what amount they would be willing to pay $(0-\$ 50, \$ 50-100, \$ 100-200,>\$ 200)$.

Following institutional review board approval we reviewed the results obtained over a four month period (July-October, 1995). Chi-square analysis was used to compare responses, $P<0.05$ was considered significant.

\section{Results}

One hundred and thirty-three QA questionnaires were distributed and $103(77 \%)$ were returned. More than $85 \%$ of respondents rated their satisfaction as excellent or very good for pain relief, convenience, applicability, and pain service follow-up. Satisfaction with PCA pain relief was higher on this occasion than the pain relief obtained from previous surgery $(P<0.001)$. More than $90 \%$ of responders said that they would request PCA again in the future and furthermore would recommend its use to others (Table I).

Patient cost estimates are shown in Figure 1. Ninety percent of patients either correctly or overestimated the cost of this service (Figure 1). Sixty percent of patients $(52 / 87)$ were willing to pay a portion of

TABLE I Values are percent, ${ }^{*} P<0.001$, pain relief $v$ p previous relief

\begin{tabular}{lccccc}
\hline \multicolumn{5}{c}{ Questionnaire Responses $^{\circ}$} \\
\hline & Excellent & Very Good & Good & Fair & Poor \\
pain relief? & 46 & 41 & 11 & 2 & 1 \\
Convenience? $_{\text {applicability? }}^{56}$ & 39 & 2 & 2 & 1 \\
follow-up? & 60 & 30 & 4 & 1 & 2 \\
side effect relief? & 74 & 22 & 3 & 1 & 0 \\
previous pain relief? & 18 & 36 & 12 & 1 & 3 \\
& & 25 & 30 & 20 & 1 \\
& strongly & somewhat & somewhat & strongly \\
future rcquest? & agree & agree & disagree & disagree \\
satisfied? & 81 & 12 & 1 & & 5 \\
recommend PCA? & 90 & 9 & 1 & & 0 \\
\hline
\end{tabular}

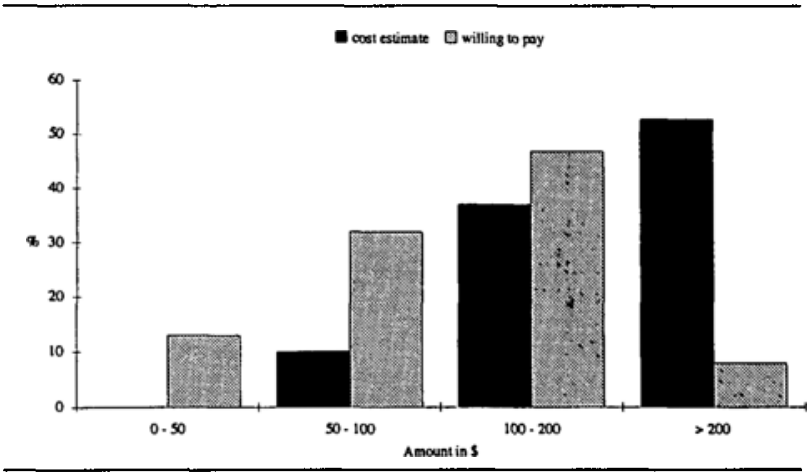

FIGURE 1 Responses to both cost estimate and willingness to pay questions. Values are \%. 
TABLE II Values are number of patients responding (\%)

\begin{tabular}{lcl}
\hline \multicolumn{3}{c}{ Payment Comparison } \\
\hline & Pay & Won't Pay \\
nausea/vomiting & $23(44)$ & $16(46)$ \\
pruritus & $20(38)$ & $18(51)$ \\
$\begin{array}{l}\text { urinary retention } \\
\text { cxcellent or very good }\end{array}$ & $12(23)$ & $8(23)$ \\
$\begin{array}{l}\text { pain relief } \\
\text { cxcellent or very good }\end{array}$ & $49(94)$ & $24(71)^{*}$ \\
$\begin{array}{c}\text { side effect treatment } \\
\text { cxcellent or very good } \\
\text { previous pain relief }\end{array}$ & $34(71)$ & $16(48)^{*}$ \\
\hline
\end{tabular}

${ }^{*} P<0.05$ Pay vs Won't Pay.

this cost (Figure 1). Seventy-eight percent of those willing to pay, would pay at least half of the cost. Those willing to pay were more likely to have had excellent or very good pain relief $(94 \%$ vs $71 \%$, $P<0.05)$ and better treatment of their side effects (71\% vs $48 \%, P<0.05$ ) (Table II).

\section{Discussion}

The initial portion of our survey supports earlier studies which noted patients' subjectively better pain relief and high degree of satisfaction with PCA when it was compared with traditional im injections. ${ }^{6}$ This is most likely due to prn pain administration still being used insufficiently, ${ }^{4}$ combined with continued nurse deficiencies in knowledge of pain management principles. 5 It is no surprise that a majority of hospital patients continue to cite pain after surgery as their primary fear. ${ }^{2}$ Patient-controlled analgesia addresses this problem because it allows patients independent control of their pain, ${ }^{11,12}$ and has, therefore, become a major component of acute pain services in Canada, ${ }^{1}$ the United States, ${ }^{2}$ and Europe. ${ }^{3}$

Our study reveals that patients are well aware of the costs involved with PCA therapy. Also, with this knowledge a majority of these patients, if necessary, are willing to pay a considerable portion of these costs to obtain this service. That patients would be willing to support this service is not surprising in view of the high degree of satisfaction with PCA as noted above. This is important in view of the recent call to demonstrate cost-effectiveness in anaesthesia. ${ }^{7}$ Though early studies suggested that PCA was more cost-effective than either $i m, 9,10$ or epidural analgesia, ${ }^{8}$ they were not conclusive. In these studies however, patients' views were not included in the analyses. Due to the diminishing funding of Canadian health care, we felt that they should be consulted regarding a service some consider a luxury.
As the questionnaire was part of a quality assurance project, one of the goals was also to improve our pain service. We found that patients who received less efficacious treatment of their PCA related side effects were less likely to be willing to pay for the service. Based on this finding, we added to our preprinted medication order sheets specific prescriptions for the treatment of nausea and vomiting, and pruritus. We plan a follow-up study to determine if any changes in patient attitudes have occurred based on these new procedures.

In summary, we reconfirmed patients' high degree of satisfaction with PCA. We also documented patients' knowledge of the cost of delivering this service as well as the fact that a majority of patients would be willing to pay a considerable portion of this cost, if necessary.

\section{Acknowledgments}

We wish to thank Catherine Hawke for the preparation of this manuscript and the members of the Department of Anaesthesia Acute Pain Service for their cooperation in undertaking this study.

\section{References}

1 Zimmerman DL, Stewart J. Postoperative pain management and Acute Pain Service activity in Canada. Can J Anaesth 1993; 40: 568-75.

2 Warfield $C A, K a h n C H$. Acute pain management. Programs in U.S. hospitals and experiences and attitudes among U.S. adults. Anesthesiology 1995; 83: $1090-4$.

3 Gould TH, Crosby DL, Harmer M, et al. Policy for controlling pain after surgery: effect of sequential changes in management. BMJ 1992; 305: 1187-93.

4 Jubl IU, Christensen BV, Bïlow HH, Wilbek $H$, Dreijer NC, Egelund B. Postoperative pain relief, from the patients' and the nurses' point of view. Acta Anaesthesiol Scand 1993; 37: 404-9.

5 Brunier G, Carson MG, Harrison DE. What do nurses know and believe about patients with pain? Results of a hospital survey. J Pain Symptom Manage 1995; 10 : 436-45.

6 Ballantyne JC, Carr DB, Chalmers TC, Dear KBG, Angelillo IF, Mosteller F. Postoperative patient-controlled analgesia: meta-analyses of initial randomized control trials. J Clin Anesth 1993; 5: 182-93.

7 Miller DR. Anaesthesia drug costs and utilization - time for a critical re-appraisal (Editorial). Can J Anaesth 1996; 43: 4-8.

8 Joshi GP. Epidural analgesia versus IV-PCA: a costbenefit analysis. Anesth Analg 1996; 82: S208. 
9 Peter EA. A cost-utility evaluation of post-operative analgesia in the elderly in a community hospital using decision analysis. Can J Anacsth 1994; 41: A22.

10 Chan VWS, Chung F, McQuestion M, Gomez M. Impact of patient-controlled analgesia on required nursing time and duration of postoperative recovery. Reg Anesth 1995; 20: 506-14.

11 Striebel $H W$, Römer $M, \operatorname{Kopf} A$, Schwagmeier R. Patient controlled oral analgesia with morphine. Can J Anaesth 1996; 43: 749-53.

12 Matas $R$. Easing pain with the push of a button. Globe and Mail, August 20, 1996; A8.

\section{Appendix}

The cost of PCA per patient was calculated by adding the costs of physician, nurse, equipment and pharmacy. Our total cost estimate was $\$ 85.50+\$ 50.00+$ $\$ 8.00+\$ 10.00$, or about $\$ 150$ per patient.

Physician cost was based on the following: patients are seen twice daily, billed a visit fee of $\$ 17.10$ and the average duration of therapy is 2.5 days. Therefore, physician cost $=2.5 \times 2 \times 17.10=\$ 85.50$. The nursing cost was estimated by dividing our nurse salary $(\$ 55,000)$ by the number of patients per year $(1,100)$ resulting in $\$ 50$ per patient. The equipment (PCA machines) cost per patient was estimated by taking the total purchase price of 22 machines $(\$ 88,000)$, assuming a ten year longevity $(\$ 8,800$ per year) and then dividing $\$ 8,800$ by the number of patients $(1,100)$; equating to $\$ 8$ per patient per year. The pharmacy uses a syringe batch filler to prepare 100 syringes at a time. The pharmacist estimated the total drug cost (including salaries), at $\$ 2.25$ per syringe. As patients approximately use $2 \mathrm{mg} \cdot \mathrm{hr}^{-1}$, over 2.5 days (60 hr) this would amount to $120 \mathrm{mg}$, and thus three syringes are required totalling $\$ 6.75$ per patient. Adding connector tubing costs of approximately $\$ 3.00$, makes a total drug cost of $\$ 10.00$ per patient. 